\title{
Effect of unifaceted and multifaceted interventions on antibiotic prescription control for respiratory diseases: a systematic review of randomized controlled trials
}

Chang Yue ( $\sim 4567401 @ q q . c o m$ )

Guizhou Medical University https://orcid.org/0000-0003-1048-6932

Zhezhe Cui

Guangxi Zhuang Autonomous Region Center for Disease Control and Prevention

Guanghong Yang

Guizhou Medical University

Xun $\mathrm{He}$

Guizhou Medical University

Lei Wang

Guizhou Provincial Health Commission

Zhang Xin

Guizhou Medical University

Lei Tang

Guizhou Medical University

\section{Research}

Keywords: Randomized controlled trial, Respiratory diseases, Antibiotic prescriptions, Systematic evaluation

Posted Date: February 12th, 2021

DOI: https://doi.org/10.21203/rs.3.rs-76757/v5

License: (c) (1) This work is licensed under a Creative Commons Attribution 4.0 International License. Read Full License 


\section{Abstract}

Background The global health system is improperly using antibiotics, particularly in the treatment of respiratory diseases. We aimed to examine the effectiveness of implementing a unifaceted and multifaceted intervention for unreasonable antibiotic prescriptions.

Methods Relevant literature published in the databases of Pubmed, Embase, Science Direct, Cochrane Central Register of Controlled Trials (CENTRAL), Chinese Journal Full-text (CNKI) and Wanfang was searched. Data were independently filtered and extracted by two reviewers based on a pre-designed inclusion and exclusion criteria. The Cochrane collaborative bias risk tool was used to evaluate the quality of the included studies.

Results A total of 1,074 relevant studies were obtained of which 69 were included in the systematic review. Fifty-nine studies reported positive results, that is, the primary results in the intervention groups were superior to those in the control groups. The remaining 10 studies had negative or partially negative results. In 22 studies the outcome variable was the antibiotic prescription rate with detailed reports of the number of prescriptions being further analyzed, of which 19 involved educational interventions for doctors, including: (1) Online training using email, web pages and webinar, (2) Antibiotic guidelines for information dissemination measures by email, postal or telephone reminder, (3) Training doctors in communication skills, (4) Short-term interactive educational seminars, and (5) Short-term field training sessions. Seventeen studies of interventions for health care workers also included: (6) Regular or irregular assessment/audit of antibiotic prescriptions, (7) Prescription recommendations from experts and peers delivered at a meeting or online, (8) Publicly reporting on doctors' antibiotic usage to patients, hospital administrators, and health authorities, (9) Monitoring/feedback prescribing behavior to general practices by email or poster, and (10) Studies involving patients and their families $(n=10)$. Seventeen studies were rated as having a low risk of bias while five were rated as having a high risk of bias.

Conclusion The combination of education, prescription audit, prescription recommendations from experts, public reporting, prescription feedback and patient or family member multifaceted interventions can effectively reduce antibiotic prescription rates in health care institutions. Moreover, adding multifaceted interventions to educational interventions can control antibiotic prescription rates and may be a more reasonable method.

Registrations: This systematic review was registered in PROSPERO, registration number: CRD42020192560.

\section{Background}

The discovery of antibacterial drugs is an important milestone in the history of human medical science. The emergence of antibiotics has changed the outcome of infections, thereby extending people's life expectancy ${ }^{[1]}$. However, in the past decade, $50 \%$ of the world's antibiotic prescriptions have been misused to treat coughs and colds, and many of these prescriptions have no indications for antibiotic use ${ }^{[2]}$. 
According to our previous research ${ }^{[3]}$, most unreasonable antibiotic prescriptions are used to treat these uncomplicated respiratory infections caused by viruses, which is common in many countries of the world $^{[4-9]}$. Therefore, if unchecked, globally, over 700,000 people will die in the next few years as a result of overuse and misuse of antibiotics and this figure could rise to 10 million by 2050, surpassing cancer as the leading cause of death ${ }^{[10,11]}$. Previous studies have shown that implementing unifaceted or multifaceted interventions for medical staff, patients and caregivers can effectively reduce antibiotic misuse and thus curb antibiotic resistance ${ }^{[12,13]}$. There are two Cochrane Systematic Reviews on interventions to improve antibiotic prescribing; one is in the ambulatory care setting ${ }^{[14]}$ and the other is among hospital inpatients ${ }^{[15]}$. The ambulatory care review has not been updated since 2005 but more recent systematic reviews have been published about interventions in primary care, especially for respiratory diseases ${ }^{[13,16,17]}$ and care homes ${ }^{[18]}$. They focused specifically on primary care institutions and physicians, or systematic reviews of educational interventions. There is strong evidence that educational interventions improve antibiotic prescribing but more evidence is required about the effectiveness of supplementing education with additional intervention elements and on the sustainability of interventions in a wider range of studies and study subjects. The antibiotic prescription rate (APR) is the main outcome indicator of interventions to control antibiotic prescriptions in those studies ${ }^{[15,17]}$.

To further confirm the effectiveness of various interventions on antibiotic prescription misuse and overuse in respiratory diseases, we used the Cochrane systematic review method to evaluate published results of relevant randomized controlled trials (RCTs) to provide a reference for relevant decision-makers.

\section{Materials And Methods}

\section{Protocol and registration}

This systematic review was conducted using the PRISMA reporting guidelines ${ }^{[25]}$ and was registered in PROSPERO with registration number CRD42020192560.

\section{Inclusion criteria}

The inclusion criteria of this study were based on the full-text information available in the English and Chinese literature databases and also included the following:

(1) The study objective focused on respiratory diseases;

(2) RCTs of intervention and control groups with measurements collected both before and after the intervention. Due to the limited literature in this research field, there was no requirement that every study be strictly randomized;

(3) Intervention targets were medical staff (general practitioners, physicians, nurses), patients and caregivers; 
(4) The interventions were clearly described.

\section{Exclusion criteria}

(1) Cross-sectional studies, cohort studies and case-control studies;

(2) System reviews, intervention protocols and letters;

(3) Duplicate studies.

\section{Selection strategy and information sources}

A systematic literature search was conducted in PubMed, Embase, Science Direct, Cochrane Central Register of Controlled Trials (CENTRAL), Chinese Journal Full-text (CNKI) and Wanfang databases. The search period was from the time of construction of the database to June 1,2020. We collected published studies in English or Chinese evaluating the effectiveness of antibiotic prescription interventions.

Keywords and search terms used included ("Antibiotic prescription" or "Antimicrobial prescription") and ("Intervention") and ("Respiratory"). Appendix 1 contains an example of the search strategy. Data were independently filtered and extracted based on the pre-designed inclusion and exclusion criteria.

\section{Study setting}

Referring to Vodicka ${ }^{[26]}$ and Roque ${ }^{[12]}$, study settings included: (1) Primary care (PC); (2) Hospital care (HP); (3) Health care center (HCc); (4) Pharmacy (PA); (5) Nursing home (NH); and (6) Clinical Practices center $(\mathrm{CPC})$.

\section{Study Design}

Study designs included: (1) Cluster randomized controlled trial (cRCT); (2) Randomized controlled trial (RCT); (3) Non-randomised and controlled trial (nRCT), where the authors performed a non-randomized controlled intervention trial; and (4) RCT/CRCT \& factorial design (FD), where the authors implemented a $\mathrm{RCT} / \mathrm{CRCT}$ for patients to receive $0,1,2$,or 3 interventions in a factorial design.

\section{Primary outcomes and findings}

The primary outcomes and findings of studies were adapted from Roque. ${ }^{[12,27]}$ The primary outcomes included: (1) Antibiotic prescription rate (APR); (2) Knowledge, attitude and practice (KAP); (3) Quality of clinical practice (QCP), which were hospitalizations, symptom duration/severity, incidence, mortality; and (4) Inappropriate rate of antibiotic (IRA). The primary findings included: (+): Positive findings; (-): Negative findings; and $( \pm)$ : The findings were both positive and negative.

\section{Summary of APR for respiratory diseases}


In the RCT studies we included, we performed a more detailed analysis if the outcome variable was the APR (defined as antibiotic prescriptions/total prescriptions $\times 100 \%$ ) and there was a detailed prescription quantity report or it could be inferred indirectly from the literature.

\section{Risk of bias assessment}

The first two authors (YC, ZZC) read the abstracts of all uncertain studies and the full-text of all studies that were still uncertain. A final agreement to include or exclude the studies was done after discussion of the discrepancies. The risk of bias in the included studies was independently assessed according to the "Cochrane systematic reviewer's manual"[28]. There are 7 items in the criteria. The bias risk assessment scoring criteria for each study were: "low risk" when all items were rated "low" or one or two of them were "unclear". If one or more items were rated "high" and more than one "unclear", it was rated as "high risk". RevMan 5.3 software was used to show the results.

\section{Results And Discussion}

The search and selection process is shown in Figure 1. A total of 1,074 relevant studies were obtained, of which 335 were excluded after reading the title and abstract. The remaining 739 studies were further screened by reading the full-text, of which 670 were excluded: 121 because they were treatment or drug intervention trials, 17 because they were antibiotic cost-benefit analysis studies, 106 because they were systematic reviews or cohort studies such as non-RCTs, 323 because they were observational studies (cross-sectional studies, and case-control studies), 96 because they were duplicate studies, and 7 studies because the full-text could not be accessed. Finally, 69 studies were included in the systematic review. In 22 studies, the outcome variable was APR and included detailed reports of the number of antibiotic prescriptions.

\section{Basic characteristics of the included studies}

As shown in Table 1, of the 69 studies included, $29^{[29-57]}$ were cluster randomized controlled trials (CRCT), $21^{[58-78]}$ were randomized controlled trials $(\mathrm{RCT}), 10^{[79-88]}$ were factorial design RCT/cRCT/nRCT, and $9^{[89-}$ ${ }^{97]}$ were non-randomised controlled trials (nRCT). Fifty-three ${ }^{[29,30,35-43, ~ 45, ~ 48-64, ~ 68, ~ 69, ~ 71-75, ~ 77-82, ~ 85-88, ~ 90-93, ~}$ 95-97] studies were conducted in primary care settings (including general practice clinics, family practices and township hospitals) and there were $7^{[31,32,34,44,66,67,70]}$ hospital-based studies. Nine ${ }^{[33,46,47,65,76,83 \text {, }}$ $84,89,94]$ studies were conducted in other settings including a health care center, nursing home and

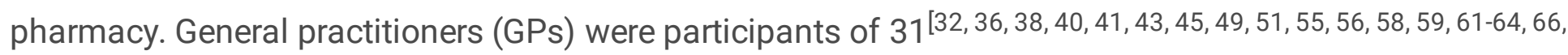
$68,72,74,75,77,78,80-82,85,90,92,96]$ intervention studies. Participants in the other 38 studies included: (1) Physicians $(n=13)^{[29,33,35,42,48,52,53,69,84,87,88,91,97]}$, doctors $(n=2)^{[70,83]}$, clinicians $(n=4)^{[34,39,60,79]}$, pharmacists $(n=4)^{[44,58,69,76]}$ and staff $(n=2)^{[46,65]}$ of day-care centers; (2) Family physicians (FPs, $\left.n=3\right)$ [30, 37, 95]; (3) Health providers (HPs, $n=5)^{[47,50,57,93,94]}$; (4) Practice providers (PPs, $\left.n=1\right)^{[89]}$, which were faculties at a clinical practices center; (5) Nurses or nurse practitioners $(n=2)^{[42,88]}$; (6) All kinds of 
patients, caregivers and inhabitants $(n=16)^{[29,31,40,42,45,46,52,54,67,71,73,85,86,88,94,97]}$. Fifty $[30-36,38,41,44$, $45,47-50,53-64,66,68,70-72,74,77,79-86,89-96]$ studies were for respiratory diseases in all patients, and the

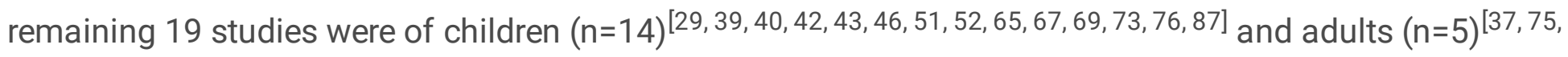
$78,88,97]$. Fifteen studies had intervention periods of less than one year. Sixty studies had positive results $\left(+\right.$, The primary results in the intervention groups were superior to those in the control groups). Nine ${ }^{[31,35,}$ $65,72,73,78,87,89,92]$ studies had negative (-) or partially negative $( \pm)$ results. The outcome variable for $37^{[29-38,40-42,45,47-51,55-59,61,63,66,70,74,77-79,84,88,92,94,96]}$ studies was APR but details were available for the intervention groups and control groups in only 22 studies (Table 2).

\section{Intervention of APR studies}

Table 2 shows intervention studies in which the outcome variable was APR. We originally planned to do a meta-analysis of RCTs, but the high heterogeneity between studies led us to perform a review of the literature descriptively.

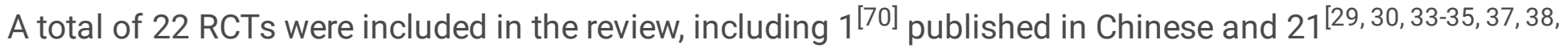
$40,45,48-50,55-58,61,66,78,92,96]$ in English. The studies involved a total of 1,878,693 prescriptions from 14 countries: China $[29,48,50,57,70]$, Australia $^{[92]}$, the United States ${ }^{[34]}$, England ${ }^{[37,38,40]}$, Canada ${ }^{[33]}$, Spain ${ }^{[61]}$, Norway ${ }^{[55]}$, Germany ${ }^{[45]}$, Netherlands ${ }^{[30,49,58]}$, Singapore ${ }^{[78]}$, Switzerland ${ }^{[35]}$, Denmark ${ }^{[96]}$, France ${ }^{[66]}$ and

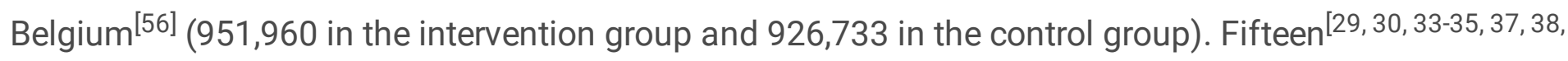
$40,45,48-50,55-57]$ studies were designed using cluster sampling and $3^{[61,92,96]}$ studies did not use random sampling, which was the main reason for the high risk of bias. Eighteen $[29,30,35,37,38,40,45,48-50,55-58,61$, $78,92,96]$ were interventions implemented at a primary care/community setting, $7[35,38,45,49,66,92,96]$ mentioned that the duration of the intervention was more than 1 year while $7[29,30,33,37,56-58]$ mentioned that the duration of the intervention was less than 1 year. Four ${ }^{[55-57,78]}$ of the study's control groups received a partial intervention. One study ${ }^{[78,99]}$ had a negative result which may be due to the fact that the interventions were targeted only at patients. Therefore, the authors suggested that future research should be aimed at GPs. Two studies had negative and positive results: Hürlimann ${ }^{[35]}$ advocated use of an intervention that included providing guidelines for the treatment of the diseases and providing sustained, regular feedback (twice a year) on individual physicians' antibiotic prescribing behavior over a two-year period, which did not reduce the APR, but increased the use of recommended antibiotics. Routine guidelines and long personal feedback intervals (twice yearly) may be the reason why the intervention was not so effective. Magin ${ }^{[92]}$ showed that a multifaceted intervention (online modules that included guidelines and communication skills and a face-to-face educational session) could reduce antibiotic prescribing for bronchitis/bronchiolitis but not upper respiratory tract infections. The study had a nonrandom sampling design that resulted in contamination in the control group resulting in no significant difference in the outcomes.

\section{Interventions of included APR studies}


Table 3 shows the categories of interventions included in the APR studies. Twenty $[29,30,33-35,37,38,40,45$, $48,49,55-58,61,66,70,92,96]$ of the 22 studies involved educational interventions, including: (1) online training using email, web pages and webinars containing guidelines and communication skills ${ }^{[40,56,92,38]}$, (2) antibiotic guidelines for information dissemination measures by email, postal or telephone reminder ${ }^{[33-35}$, $37,38,50,56,57,66,70,92]$, (3) training doctors in communication skills $[30,33,34,37,40,45,50,57,58,70,92,96]$, short-term interactive educational seminars ${ }^{[29,34,38,49,55,58,61,66,70,92]}$ and (5) short-term field training sessions $^{[29,34,49,55,58,61,66,70,92,96]}$, the latter two types of training methods were generally face-to-face (on-site) interventions and the duration was usually hours or days of diagnostic and drug guidances, rapid testing method, of which $6^{[34,38,58,66,70,92]}$ studies comprehensively used more than 2 educational interventions, and all of these studies had positive results.

Seventeen studies of interventions for health care workers also included: (6) regular or irregular assessment/audit of antibiotic prescriptions ${ }^{[29,33,38,55,61,70,96,]}$, and (7) prescription recommendations from experts and peers delivered at a meeting or online. ${ }^{[30,33,34,45,49,56]}$ Vervloet ${ }^{[30]}$ implemented a prescription recommendation in an Electronic Prescribing System (EPS). When a family physician tried to prescribe an antibiotic to a patient with RTI, the EPS immediately prompted an alert with the message "no prescription", and if the doctor still wanted a prescription, a pop up window containing the message "delayed prescription" would appear. After acknowledging these two electronic alerts, the doctor could write a prescription. (8) Two studies reported publicly on doctors' antibiotic usage to patients, hospital administrators, and health authorities. The report contained APR, injection for APR, cost and peer ranking. [48, 50] (9) Eight studies reported moniotoring/feedback prescribing behaviour to GPs by email or poster (the prescribing behaviour of individual physicians for 6 months or one year) ${ }^{[30,33-35,38,48,55,58]}$.

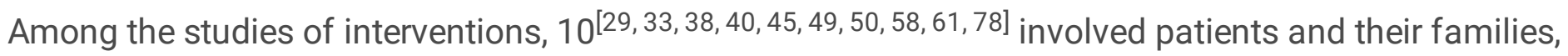
including the distribution of leaflets and brochures on the rational use of antibiotics, the installation of multimedia education systems or poster/video in waiting rooms, and the use of flyers and posters. One ${ }^{[78]}$ of the studies involved only patients and family members.

\section{Risk of bias}

Seventeen $^{[29,30,34,35,37,38,40,45,48-50,55-58,66,78]}$ studies were rated as having a low risk of bias while $5^{[33,}$ $61,70,92,96]$ were rated as having a high risk of bias. Figure 2 shows the risk of bias assessment for each criterion. Among the 22 studies, $4^{[61,70,92,96]}$ in the "Random Sequence Generation" section were determined to have a high risk of bias as three of the studies were non-random sampling and one did not describe the sampling method. One study was identified as having a high risk of bias in the "Allocation concealment", [92] "Blinding of participants and personnel" ${ }^{[33]}$ section due to a lack of random sampling and unblinded nature.

\section{Evaluation of publication bias}


Figure 3 shows an inverted funnel chart, which has poor symmetry and suggests a high level of publication bias.

\section{Conclusions}

Our findings indicate that the majority $(52,75 \%)$ of RCTs on antibiotic prescriptions for respiratory tract infections were conducted in primary health care settings. GPs and physicians were the main subjects of the intervention. Fifty-one studies (74\%) did not have a specific population with the diseases and had intervention periods of less than 1 year. There were 37 studies that had an APR as the outcome variable. Patient-only, long feedback intervals, non-random sampling and non-blind nature of the intervention may have led to negative results and a high risk of bias.

A further analysis of 22 studies in which the outcome variable was APR found that all but one were multifaceted interventions. Educational methods were the most common interventions. Among them, the distribution of antibiotic guidelines to doctors, short training sessions of one to several days and training in doctors' communication skills were the most common educational interventions, and they were often used in combination. In addition, interventions for health care workers included monitoring and feedback of doctors' prescribing performance to them, auditing or evaluating the rationality of prescriptions, and prescribing recommendations from experts or via an electronic prescribing system. On the basis of the above interventions, some were added to the intervention of patients or caregivers. However, it is important to note that patients cannot be given an intervention alone, or the intervention may face ineffective results. In addition, these 22 RCTs studies investigated a wide range of interventions targeted at both clinicians and patients (education, guidelines, prescriber feedback, patient pamphlets, etc.). This makes it very difficult to meta-analyse and to interpret the results as it's unclear exactly which intervention targeted at which groups and in what setting is having the impact on prescribing. It also explains why there are such high rates of heterogeneity.

In summary, multifaceted feedback interventions were used in most of the included studies. Therefore, the education and training of doctors in prescribing antibiotics should be strengthened, organized medical staff should delve deep into the rules and regulations of antibiotics, and make full use of pharmacology, pharmacokinetics, pharmacodynamics, and other relevant knowledge to issue prescriptions ${ }^{[108,109]}$. On this basis, various feedback interventions can be added, such as communication between experts and peers, prescription audits, and ranking of doctors in the same department. In addition, interventions can improve the awareness of patients and their families toward antibiotics, such as providing them with brochures and leaflets, displaying posters in the waiting rooms, installing a multimedia education system in waiting areas, and encouraging patients to communicate more with their physicians about the use of antibiotics. Dekker ${ }^{[40]}$, Llor ${ }^{[103]}$, and Metlay ${ }^{[34]}$ adopted certain intervention measures for patients and their families based on educational intervention measures for medical staff. Altiner ${ }^{[45]}$ studied patients and their families based on using feedback intervention for medical staff, and the degree of reduction of antibiotic utilization was significantly higher than in other studies. Therefore, according to education and training interventions, feedback interventions were used to 
influence the prescribing behavior of doctors and improve the cognition of patients and their families about antibiotics. This multivariate behavioral feedback intervention might be a more rational approach to antibiotic prescription control. In terms of policymaking, health administration departments should introduce regulations and relevant policies on the administration of antibiotics to strictly control the use of antibiotics. These departments can take strong administrative interventions against the unreasonable use of antibiotics, for example, patients or consumers could only obtain antibiotics from the pharmacies based on prescriptions, and doctors can prescribe antibiotics in a hierarchical manner.

Our study has certain limitations. First, like most systematic reviews, there is a possibility of publication bias. We analyzed only 69 of the studies with basic characteristics, and 22 of the studies further focused were all positive outcomes. We concluded from these 22 studies that multifaceted interventions are more effective in reducing antibiotic prescription rates. Furthermore, some studies were not included due to incomplete data. This limitation may have reduced the objectivity of the results to a certain extent. Second, there were different degrees of quality differences in the design of the included studies, which may have affected our results. Third, these studies were conducted in different countries. The policies and management systems of antibiotic use differ by country, thus there was a risk of information bias. Fourthly, we only focused on the APR, but did not pay attention to the rational evaluation of antibiotics.

This systematic review found that combination of education, prescription audit, prescription recommendations from experts, public reporting, prescription feedback and patient or family member interventions and other multifaceted feedback interventions can effectively reduce the rate of antibiotic prescriptions and promote the rational use of antibiotics. However, due to the above limitations, we can only conclude that adding multifaceted feedback interventions to education interventions may be a more reasonable control method. In the future, more studies need to be included to obtain more accurate information.

\section{Abbreviations}

CENTRAL: Cochrane Central Register of Controlled Trials;

APR: Antibiotic prescription rate;

CNKI: Chinese Journal Full-text;

RD: Risk difference;

Cl: Confidence interval;

RCTs: Randomized Controlled Trials;

RTIs: Respiratory tract infections $\rrbracket$

RCTs: randomized controlled trials; 
PC: Primary care;

HP: Hospital care;

HCc: Health care center;

PA: Pharmacy;

NHs: Nursing homes;

CPc: Clinical Practices center

cRCT: Cluster randomized control trial;

RCT: Randomized controlled trial;

nRCT: Non-randomised and controlled trial;

FD: Factorial design;

KAP: Knowledge, Attitude and Practice (KAP);

QCP: Quality of clinic practice;

PRE: Prescription evaluation

IRA: Inappropriate rate of antibiotic;

URTIs: Upper respiratory tract infections;

LRTIs: Lower respiratory tract infections;

ARTIs: Acute respiratory tract infections;

IDs: Infectious diseases;

UTIs: Urinary tract infections;

TB: Tuberculosis;

COPD: Chronic obstructive pulmonary disease;

CAP: Community-acquired pneumonia;

GPs: General practitioners;

FPs: Family physicians; 
HPs: Health providers;

PPs: Practice providers;

NPs: Nurses or nurse practitioners.

\section{Declarations}

\section{Conflict of Interest}

All authors have no conflicts of interest to declare.

\section{Consent for publication}

Not applicable.

\section{Availability of data and materials}

Not applicable.

\section{Authors' contributions}

All authors made substantial contributions to the development of the trial, and read and approved the final manuscript. YC, ZZC, GHY designed the trial. XZ drafted the manuscript, and YC and ZZC completed data extraction, statistical analysis and data interpretation. GHY and LT participated in the concept, data interpretation and manuscript revision. $\mathrm{YC}$ is responsible for data integrity and accuracy of data analysis.

\section{Acknowledgments}

We thank all of the participating institutions for providing information and assistance during the study. The authors also thank all members of the investigational team who collected the data. English grammar were revised from Edward McNeil, Prince of Songkla University, Songkhla, Thailand.

This study was due to a grant obtained from the National Natural Science Foundation of China Grant on "Research on feedback intervention mode of antibiotic prescription control in primary medical institutions based on the depth graph neural network technology" (71964009) and the Science and Technology Fund Project of Guizhou Provincial Health Commission Grant on "Application Research of Deep Learning Technology in Rational Evaluation and Intervention of Antibiotic Prescription" (gzwjkj2019-1-218).

\section{Funding}

The study was funded by the National Natural Science Foundation of China Grant on "Research on feedback intervention mode of antibiotic prescription control in primary medical institutions based on the depth graph neural network technology" (71964009) and the Science and Technology Fund Project of 
Guizhou Provincial Health Commission Grant on "Application Research of Deep Learning Technology in Rational Evaluation and Intervention of Antibiotic Prescription" (gzwjkj2019-1-218).

\section{Ethical approval}

This study was approved by the Academic Committee of Guizhou Medical University. All participants provided written informed consent

\section{Appedix 1}

An example of a search strategy (Pubmed database search strategy)

\section{References}

[1]World Health Organization. Global antimicrobial resistance surveillance system (GLASS) report 20172018. 2018.

[2]World Health Organization. Antimicrobial Resistance Global Report on surveillance 2014. 2014.

[3]Chang Y, Chusri S, Sangthong R, et al. Clinical pattern of antibiotic overuse and misuse in primary healthcare hospitals in the southwest of China. PLoS One. $2019 ; 14(6): \mathrm{e} 0214779$.

[4]Bianco A, Papadopoli R, Mascaro V,et al. Antibiotic prescriptions to adults with acute respiratory tract infections by Italian general practitioners. Infect Drug Resist. 2018;11:2199-2205.

[5]Durkin MJ, Jafarzadeh SR, Hsueh K,et al. Outpatient Antibiotic Prescription Trends in the United States: A National Cohort Study. Infect Control Hosp Epidemiol. 2018;39(5):584-589.

[6]Sharma P, Finley R, Weese S, et al. Antibiotic prescriptions for outpatient acute rhinosinusitis in Canada, 2007-2013. PLoS One. 2017;12(7):e0181957.

[7]Butt AA, Navasero CS, Thomas B, et al. Antibiotic prescription patterns for upper respiratory tract infections in the outpatient Qatari population in the private sector. Int J Infect Dis. 2017;55:20-23.

[8]Sun Q, Dyar OJ, Zhao L, et al. Overuse of antibiotics for the common cold - attitudes and behaviors among doctors in rural areas of Shandong Province, China. BMC Pharmacol Toxicol. 2015;16:6.

[9]Lindberg $\mathrm{BH}$, Gjelstad $\mathrm{S}$, Foshaug $\mathrm{M}$, et al. Antibiotic prescribing for acute respiratory tract infections in Norwegian primary care out-of-hours service. Scand J Prim Health Care.2017;35(2):178-185.

[10]World Health Organization. Antibiotic prescribing and resistance: Views from low- and middle-income prescribing and dispensing professionals.2017.

[11]Bush K, Courvalin P, Dantas G, et al. Tackling antibiotic resistance. Nature Reviews Microbiology.2011;9(12):894-896. 
[12]Roque F, Herdeiro MT, Soares S, et al. Educational interventions to improve prescription and dispensing of antibiotics: a systematic review. BMC Public Health. 2014;14:1276.

[13]Köchling A, Löffler $C$, Reinsch S, et al. Reduction of antibiotic prescriptions for acute respiratory tract infections in primary care: a systematic review. Implement Sci. 2018;13(1):47.

[14]Arnold SR, Straus SE. Interventions to improve antibiotic prescribing practices in ambulatory care. Cochrane Database Syst Rev. 2005;2005(4):CD003539.

[15]Davey P, Marwick CA, Scott CL, et al. Interventions to improve antibiotic prescribing practices for hospital inpatients. Cochrane Database Syst Rev. 2017;2(2):CD003543.

[16]Roque F, Herdeiro MT, Soares S, et al. Educational interventions to improve prescription and dispensing of antibiotics: a systematic review. BMC Public Health. 2014;14:1276.

[17]Van der Velden AW, Pijpers EJ, Kuyvenhoven MM, et al. Effectiveness of physician-targeted interventions to improve antibiotic use for respiratory tract infections. Br J Gen Pract. 2012;62(605):e801807.

[18]Nguyen HQ, Tunney MM, Hughes CM. Interventions to Improve Antimicrobial Stewardship for Older People in Care Homes: A Systematic Review. Drugs Aging. 2019;36(4):355-369.

[19]Hux JE, Melady MP, DeBoer D. Confidential prescriber feedback and education to im-prove antibiotic use in primary care: a controlled trial. Canadian Medical Association Jour-nal. 1999;161(4):388-392.

[20]Elouafkaoui P, Young L, Newlands R, et al. An Audit and Feedback Intervention for Reducing Antibiotic Prescribing in General Dental Practice: The RAPiD Cluster Randomised Controlled Trial. PLoS Med. 2016;13(8):e1002115.

[21]Freedberg DE, Salmasian $\mathrm{H}$, Abrams JA, et al. Orders for intravenous proton pump inhibitors after implementation of an electronic alert. Jama Internal Medicine. 2015;175(3):452-454.

[22]Hallsworth M, Chadborn T, Sallis A, et al. Provision of social norm feedback to high prescribers of antibiotics in general practice: a pragmatic national randomised controlled trial. Lancet. 2016;387(10029):1743-1752.

[23]Kandel CE, Gill S, McCready J, et al. Reducing co-administration of proton pump inhibitors and antibiotics using a computerized order entry alert and prospective audit and feedback. BMC Infect Dis. 2016;16:355.

[24]Tamma PD, Avdic E, Keenan JF, et al. What Is the More Effective Antibiotic Stewardship Intervention: Preprescription Authorization or Postprescription Review With Feedback? Clin Infect Dis. 2017;64(5):537543. 
[25]Moher D, Liberati A, Tetzlaff J, et al. Preferred reporting items for systematic reviews and metaanalyses: the PRISMA statement. The British Medical Journal. 2009;339:b2535.

[26]Vodicka TA, Thompson M, Lucas $P$, et al. Reducing antibiotic prescribing for children with respiratory tract infections in primary care: a systematic review. Br J Gen Pract. 2013;63(612):e445-454.

[27]Steinman MA, Ranji SR, Shojania KG, et al. Improving antibiotic selection: a systematic review and quantitative analysis of quality improvement strategies. Med Care. 2006;44(7):617-628.

[28] Cochrane Center of China, West China Hospital of Sichuan University, Evidence-based Medicine Center of Lanzhou University, Cochrane Intervention Department Evaluation Handbook. 2014.

[29]Wei X, Zhang Z, Walley JD, et al. Effect of a training and educational intervention for physicians and caregivers on antibiotic prescribing for upper respiratory tract infections in children at primary care facilities in rural China: a cluster-randomised controlled trial. Lancet Glob Health. 2017;5(12):e1258e1267.

[30]Vervloet M, Meulepas MA, Cals JW, et al. Reducing antibiotic prescriptions for respiratory tract infections in family practice: results of a cluster randomized controlled trial evaluating a multifaceted peer-group-based intervention. NPJ Prim Care Respir Med. 2016;26:15083.

[31]van de Maat JS, Peeters D, Nieboer D, et al. Evaluation of a clinical decision rule to guide antibiotic prescription in children with suspected lower respiratory tract infection in The Netherlands: A steppedwedge cluster randomised trial. PLoS Med. 2020;17(1):e1003034.

[32]Schouten JA, Hulscher ME, Trap-Liefers J, et al. Tailored interventions to improve antibiotic use for lower respiratory tract infections in hospitals: a cluster-randomized, controlled trial. Clin Infect Dis. 2007;44(7):931-941.

[33]Monette J, Miller MA, Monette M,et al. Effect of an educational intervention on optimizing antibiotic prescribing in long-term care facilities. J Am Geriatr Soc. 2007;55(8):1231-1235.

[34]Metlay JP, Camargo CA Jr, MacKenzie T, et al. Cluster-randomized trial to improve antibiotic use for adults with acute respiratory infections treated in emergency departments. Ann Emerg Med. 2007;50(3):221-230.

[35]Hürlimann D, Limacher A, Schabel M, et al. Improvement of antibiotic prescription in outpatient care: a cluster-randomized intervention study using a sentinel surveillance network of physicians. J Antimicrob Chemother. 2015;70(2):602-608.

[36]Høye S, Gjelstad S, Lindbæk M. Effects on antibiotic dispensing rates of interventions to promote delayed prescribing for respiratory tract infections in primary care. Br J Gen Pract. 2013;63(616):e777786. 
[37]Gulliford MC, van Staa T, Dregan A, et al. Electronic health records for intervention research: a cluster randomized trial to reduce antibiotic prescribing in primary care (eCRT study). Ann Fam Med. 2014 ;12(4):344-351.

[38]Gulliford MC, Prevost AT, Charlton J, et al. Effectiveness and safety of electronically delivered prescribing feedback and decision support on antibiotic use for respiratory illness in primary care: REDUCE cluster randomised trial. BMJ. $2019 ; 12: 364$.

[39]Francis NA, Butler CC, Hood K, et al. Effect of using an interactive booklet about childhood respiratory tract infections in primary care consultations on reconsulting and antibiotic prescribing: a cluster randomised controlled trial. BMJ. $2009 ; 29: 339$.

[40]Dekker ARJ, Verheij TJM, Broekhuizen BDL, et al. Effectiveness of general practitioner online training and an information booklet for parents on antibiotic prescribing for children with respiratory tract infection in primary care: a cluster randomized controlled trial. J Antimicrob Chemother. 2018 ;73(5):1416-1422.

[41]Butler CC, Simpson SA, Dunstan F, et al. Effectiveness of multifaceted educational programme to reduce antibiotic dispensing in primary care: practice based randomised controlled trial. BMJ. 2012;344.

[42]Bourgeois FC, Linder J, Johnson SA, et al. Impact of a computerized template on antibiotic prescribing for acute respiratory infections in children and adolescents. Clin Pediatr (Phila). 2010;49(10):976-983.

[43]Blair PS, Turnbull S, Ingram J, et al. Feasibility cluster randomised controlled trial of a withinconsultation intervention to reduce antibiotic prescribing for children presenting to primary care with acute respiratory tract infection and cough. BMJ Open. 2017;7(5):e014506.

[44]Ashiru-Oredope D, Doble A, Thornley T, et al. Improving Management of Respiratory Tract Infections in Community Pharmacies and Promoting Antimicrobial Stewardship: A Cluster Randomised Control Trial with a Self-Report Behavioural Questionnaire and Process Evaluation. Pharmacy (Basel). 2020 ;8(1):44.

[45]Altiner A, Brockmann S, Sielk M, et al. Reducing antibiotic prescriptions for acute cough by motivating GPs to change their attitudes to communication and empowering patients: a cluster-randomized intervention study. J Antimicrob Chemother. 2007;60(3):638-644.

[46]Azor-Martinez E, Yui-Hifume R, Muñoz-Vico FJ, et al. Effectiveness of a Hand Hygiene Program at Child Care Centers: A Cluster Randomized Trial. Pediatrics. 2018 ;142(5):e20181245.

[47]Temime L, Cohen N, Ait-Bouziad K, et al. Impact of a multicomponent hand hygiene-related intervention on the infectious risk in nursing homes: A cluster randomized trial. Am J Infect Control. 2018 Feb;46(2):173-179. 
[48]Tang Y, Liu C, Zhang X. Performance associated effect variations of public reporting in promoting antibiotic prescribing practice: a cluster randomized-controlled trial in primary healthcare settings. Prim Health Care Res Dev. 2017;18(5):482-491.

[49]van der Velden AW, Kuyvenhoven MM, Verheij TJ. Improving antibiotic prescribing quality by an intervention embedded in the primary care practice accreditation: the ARTI4 randomized trial. J Antimicrob Chemother. 2016;71(1):257-263.

[50]Yang L, Liu C, Wang L, et al. Public reporting improves antibiotic prescribing for upper respiratory tract infections in primary care: a matched-pair cluster-randomized trial in China. Health Res Policy Syst. $2014 ; 12$.

[51]Gerber JS, Prasad PA, Fiks AG, et al. Effect of an outpatient antimicrobial stewardship intervention on broad-spectrum antibiotic prescribing by primary care pediatricians: a randomized trial. JAMA. 2013;309(22):2345-2352.

[52]Finkelstein JA, Huang SS, Kleinman K, et al. Impact of a 16-community trial to promote judicious antibiotic use in Massachusetts. Pediatrics. 2008 ;121(1):e15-e23.

[53]Monette J, Miller MA, Monette M, et al. Effect of an educational intervention on optimizing antibiotic prescribing in long-term care facilities. J Am Geriatr Soc. 2007;55(8):1231-1235.

[54]Fairall LR, Zwarenstein M, Bateman ED, et al. Effect of educational outreach to nurses on tuberculosis case detection and primary care of respiratory illness: pragmatic cluster randomised controlled trial. BMJ. $2005 ; 331(7519): 750-754$.

[55]Gjelstad S, Hoye S, Straand J, et al. Improving antibiotic prescribing in acute respiratory tract infections: cluster randomised trial from Norwegian general practice (prescription peer academic detailing (Rx-PAD) study). BMJ. 2013; 347: f4403.

[56]Coenen S, Van Royen P, Michiels B, et al. Optimizing antibiotic prescribing for acute cough in general practice: a cluster-randomized controlled trial. Journal of Antimicrobial Chemotherapy. 2004; 54(3): 661672.

[57]Chen $\mathrm{Y}$, Yang $\mathrm{K}$, Jing $\mathrm{T}$, et al. Use of text messages to communicate clinical recommendations to health workers in rural China: a cluster-randomized trial. Bulletin of the World Health Organization. 2014; 92(7): 474-481.

[58]Welschen I, Kuyvenhoven MM, Hoes AW, et al. Effectiveness of a multifaceted intervention to reduce antibiotic prescribing for respiratory tract symptoms in primary care: randomised controlled trial. BMJ. 2004; 329(7463): 431.

[59]Milos V, Jakobsson U, Westerlund T, et al. Theory-based interventions to reduce prescription of antibiotics-a randomized controlled trial in Sweden. Family Practice. 2013; 30(6): 634-640. 
[60]Meeker D, Knight TK, Friedberg M, et al. Nudging guideline-concordant antibiotic prescribing: a randomized clinical trial. JAMA Internal Medicine. 2014; 174(3): 425-431.

[61] Llor C, Cots JM, et al. Interventions to reduce antibiotic prescription for lower respiratory tract infections: Happy Audit study. European Respiratory Journal. 2012; 40(2): 436-441.

[62] Little P, Stuart B, Andreou P, et al. Primary care randomised controlled trial of a tailored interactive website for the self-management of respiratory infections (Internet Doctor). BMJ Open. 2016; 6(4): e009769.

[63]Le Corvoisier P, Renard V, Roudot Thoraval F, et al. Long-term effects of an educational seminar on antibiotic prescribing by GPs: a randomised controlled trial. British Journal of General Practice. 2013; 63(612): 455-464.

[64]Jenkins TC, Irwin A, Coombs L, et al. Effects of clinical pathways for common outpatient infections on antibiotic prescribing. American Journal of Medicine. 2013; 126(4): 327-335.

[65]Hedin K, Petersson C, Cars H, et al. Infection prevention at day-care centres: feasibility and possible effects of intervention. Scandinavian Journal of Primary Health Care. 2006; 24(1): 44-49.

[66]Ferrat E, Le Breton J, et al. Effects 4.5 years after an interactive GP educational seminar on antibiotic therapy for respiratory tract infections: a randomized controlled trial. Family Practice. 2016; 33(2): 192199.

[67]Angoulvant $F$, Rouaul $A$, et al. Randomized controlled trial of parent therapeutic education on antibiotics to improve parent satisfaction and attitudes in a pediatric emergency department. PLoS One. 2013; 8(9): e75590.

[68]Shen XR, Lu MM, Feng R,et al. Web-Based Just-in-Time Information and Feedback on Antibiotic Use for Village Doctors in Rural Anhui, China: Randomized Controlled Trial.. Journal of medical Internet research. 2018; 20(2).

[69]Hoa NQ, Thi Lan P, Phuc HD, et al. Antibiotic prescribing and dispensing for acute respiratory infections in children: effectiveness of a multi-faceted intervention for health-care providers in Vietnam.. Global Health Action. 2017; 10(1): 1327638.

[70] Qiu JG. A review of the significance of clinical application of antibiotics and pharmaceutical. Intervention in respiratory Medicine. 2016; 14 (21) : 105-106.

[71]Little P, Stuart B, Hobbs FDR, et al. An internet-delivered handwashing intervention to modify influenza-like illness and respiratory infection transmission (PRIMIT): a primary care randomised trial. The Lancet. 2015; 386(10004): 1631-1639. 
[72]Smeets HM, Kuyenhoven M, Akkerman A, et al. Intervention with educational outreach at large scale to reduce antibiotics for respiratory tract infections: a controlled before and after study.. Family Practice. 2009; 26(3): 183-187.

[73]Taylor JA, Kwan-Gett TS, McMahon EM Jr, et al. Effectiveness of a Parental Educational Intervention in Reducing Antibiotic Use in Children: A Randomized Controlled Trial.. The Pediatric Infectious Disease Journal. 2005;24(6):489-493

[74]Wilson EJ, Nasrin D, Dear KB, et al. Changing GPs' antibiotic prescribing: a randomised controlled trial.. Communicable diseases intelligence quarterly report. 2003;27 Suppl:S32-8.

[75]Macfarlane J, Holmes W, Gard P, et al. Reducing antibiotic use for acute bronchitis in primary care: blinded, randomised controlled trial of patient information leaflet.. BMJ. 2002 ;324(7329):91-94.

[76]Chalker J, Chuc NT, Falkenberg T, et al. Private pharmacies in Hanoi, Vietnam: a randomized trial of a 2-year multi-component intervention on knowledge and stated practice regarding ARI, STD and antibiotic/steroid requests.. Tropical Medicine \& International Health. 2002;7(9): 803-810.

[77]Zwar N, Wolk J, Gordon J, et al. Influencing antibiotic prescribing in general practice: a trial of prescriber feedback and management guidelines.. Family practice. 1999;16(5):495-500.

[78]Lee MHM, Pan DST, Huang JH, et al. Results from a Patient-Based Health Education Intervention in Reducing Antibiotic Use for Acute Upper Respiratory Tract Infections in the Private Sector Primary Care Setting in Singapore.. Antimicrobial Agents and Chemotherapy. 2017;61(5):e02257-16.

[79]Meeker D, Linder JA, Fox CR, et al. Effect of Behavioral Interventions on Inappropriate Antibiotic Prescribing Among Primary Care Practices: A Randomized Clinical Trial. JAMA.2016;315(6):562-570.

[80]Little P, Stuart B, Francis N. et al. Effects of internet-based training on antibiotic prescribing rates for acute respiratory-tract infections: a multinational, cluster, randomised, factorial, controlled trial. The Lancet,.2013;382(9899):1175-1182.

[81]Hrisos S, Eeccles M, Johnston M, et al., An intervention modelling experiment to change GPs' intentions to implement evidence-based practice: using theory-based interventions to promote GP management of upper respiratory tract infection without prescribing antibiotics \#2. BMC Health Services Research. 2008:10.

[82]Treweek S, Francis JJ, Bonetti D, et al. A primary care Web-based Intervention Modeling Experiment replicated behavior changes seen in earlier paper-based experiment.. Journal of clinical epidemiology. 2016;80:116-122.

[83]Chowdhury A.K, Matin M.A, Begum K, et al.Effect of standard treatment guidelines with or without prescription audit on prescribing for acute respiratory tract infection (ARI) and diarrhoea in some thana health complexes (PCs) of Bangladesh.. Bangladesh Medical Research Council bulleti.2007; 33(1): 21-30. 
[84]Gonzales R, Corbett KK, Leeman-Castillo BA, et al. The "minimizing antibiotic resistance in Colorado" project: impact of patient education in improving antibiotic use in private office practices.. Health services research. 2005;40(1):101-116.

[85]Samore MH, Bateman K, Alder SC, et al. Clinical Decision Support and Appropriateness of Antimicrobial Prescribing: A Randomized Trial.. JAMA: The Journal of the American Medical Association. 2005;294(18):2305-2314.

[86]Paul L, Rumsby K, Kelly J, et al. Information Leaflet and Antibiotic Prescribing Strategies for Acute Lower Respiratory Tract Infection: A Randomized Controlled Trial.. JAMA: The Journal of the American Medical Association. 2005;(24):3029-3035.

[87]Maus AG, Hueston WJ, Love MM, et al. An evaluation of statewide strategies to reduce antibiotic overuse.. Family medicine. 2000;32(1):22-29.

[88]Ralph G, Steiner JF, Lum A,et al. Decreasing Antibiotic Use in Ambulatory Practice: Impact of a Multidimensional Intervention on the Treatment of Uncomplicated Acute Bronchitis in Adults.. JAMA: The Journal of the American Medical Association. 1999;281(16):1512-1519.

[89]Vinnard C, Linkin DR, Localio AR, et al. Effectiveness of Interventions in Reducing Antibiotic Use for Upper Respiratory Infections in Ambulatory Care Practices. Population Health Management. 2013;16(1):22-27.

[90]Munck AP, Gahrn-Hansen B, Søgaard P, et al. Long-lasting improvement in general practitioners' prescribing of antibiotics by means of medical audit. Scand J Prim Health Care. 1999;17(3):185-190.

[91]Juzych NS, Banerjee M, Essenmacher L, et al. Improvements in antimicrobial prescribing for treatment of upper respiratory tract infections through provider education. J Gen Intern Med, 2005; 20(10): 901-905.

[92]Magin P, Tapley A, Morgan S, et al. Reducing early career general practitioners' antibiotic prescribing for respiratory tract infections: a pragmatic prospective non-randomised controlled trial. Family practice,2018; 35.1: 53-60.

[93]Milani RV, Wilt JK, Entwisle J, et al. Reducing inappropriate outpatient antibiotic prescribing: normative comparison using unblinded provider reports. BMJ Open Quality,2019;8(1).

[94]Zimmerman S, Sloane PD, Bertrand R, et al. Successfully reducing antibiotic prescribing in nursing homes. Journal of the American Geriatrics Society,2014;62.5: 907-912.

[95]Reyes-Morales H, Flores-Hernandez S, Tome-Sandoval P, et al. A multifaceted education intervention for improving family physicians' case management. Family medicine,2009;41.4: 277.

[96]Bjerrum L, Cots JM, Llor C, et al. Effect of intervention promoting a reduction in antibiotic prescribing by improvement of diagnostic procedures: a prospective, before and after study in general practice. 
European Journal of Clinical Pharmacology,2006;62.11: 913.

[97]Harris RH, Mac Kenzie TD, Leeman-Castillo B, et al. Optimizing antibiotic prescribing for acute respiratory tract infections in an urban urgent care clinic. Journal of General Internal Medicine,2003;18.5: 326-334.

[98]Lee MHM, Pan DST, Huang JH, et al., Results from a Patient-Based Health Education Intervention in Reducing Antibiotic Use for Acute Upper Respiratory Tract Infections in the Private Sector Primary Care Setting in Singapore. Antimicrob Agents Chemother, 2017. 61(5).

[99]Llor C, Bjerrum L, Molero JM, et al. Long-term effect of a practice-based intervention (HAPPY AUDIT) aimed at reducing antibiotic prescribing in patients with respiratory tract infections. Journal of Antimicrobial Chemotherapy, 2018;73.8: 2215-2222.

[100] Luo M, Wei SB, Huang L, et al. Systematic evaluation and meta-analysis of kangfu antiinflammatory suppository combined with antibiotics in the treatment of pelvic inflammatory disease.Chinese Journal of Antibiotics. 2019; 44 (4) : 519-526

[101] Tang YQ, Du X, Wang HT, et al.Meta analysis of the effect of comprehensive intervention on reducing the utilization rate of antibacterial drugs in inpatients.China pharmacy, 2013; 24(24): 2275-2279.

\section{Tables}

Due to technical limitations Tables $1-3$ are available as downloads in the Supplementary Files.

\section{Figures}




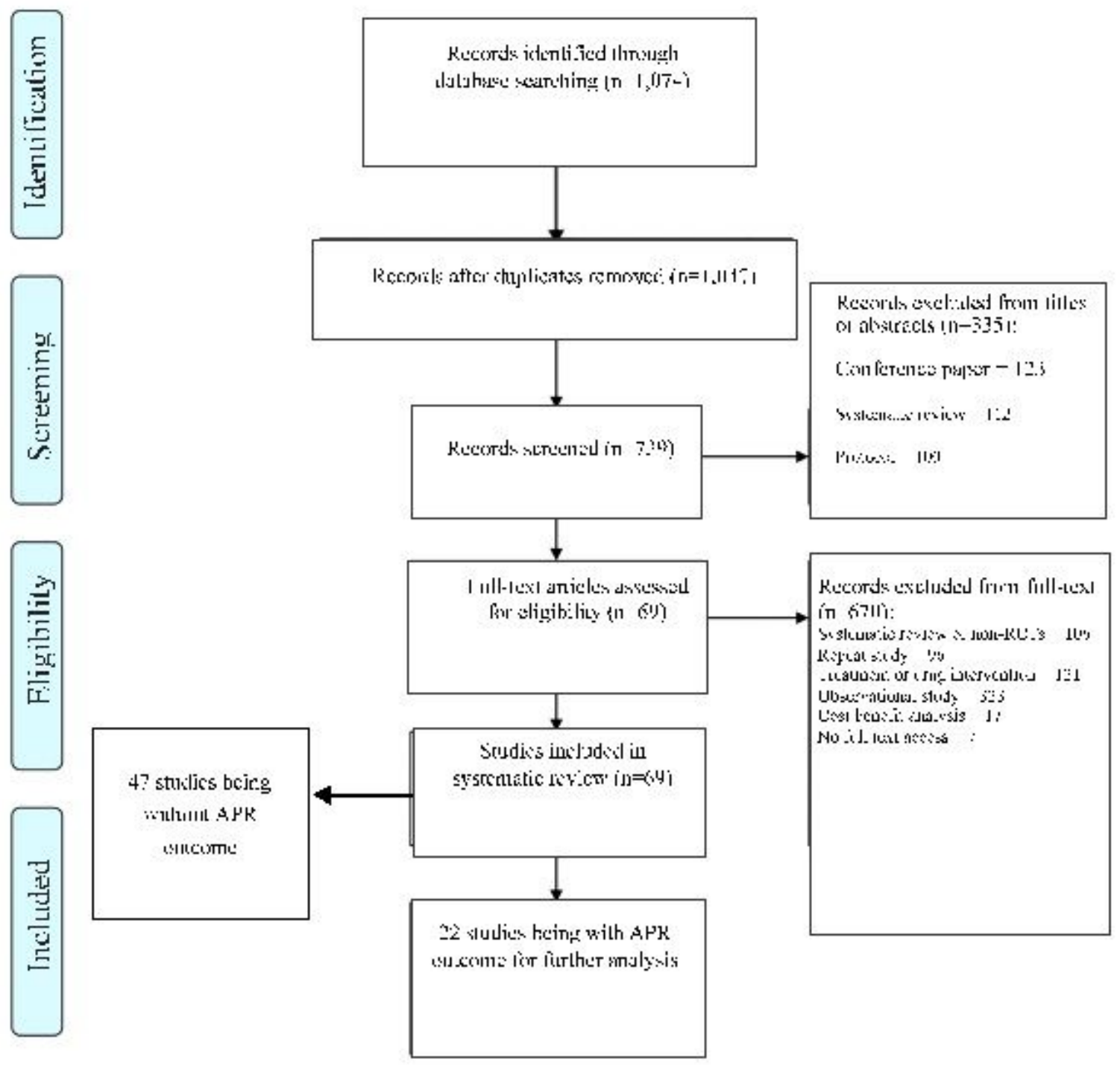

Figure 1

PRISMA screening flow chart 


\begin{tabular}{|c|c|c|c|c|c|c|c|}
\hline & 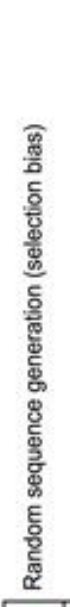 & 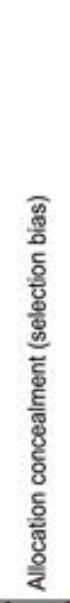 & 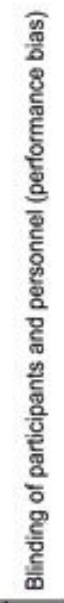 & 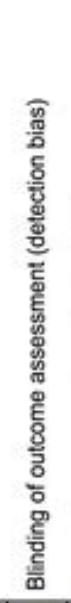 & 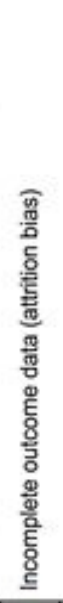 & 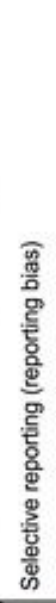 & 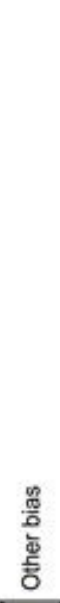 \\
\hline Coenen S,Belgium,2004 & 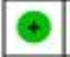 & $\odot$ & $\odot$ & $?$ & $\odot$ & $\odot$ & $?$ \\
\hline Ineke W.Netherland,2004 & + & $\odot$ & $\odot$ & $\odot$ & $\odot$ & (4) & $\odot$ \\
\hline Bjerrum L.Denmark,2006 & 0 & $?$ & $?$ & $?$ & $?$ & $\odot$ & $?$ \\
\hline Altiner A,Germany,2007 & $\odot$ & $?$ & $?$ & $\odot$ & $\odot$ & $\odot$ & ( \\
\hline Metlay J.P.USA,2007 & \begin{tabular}{|c|}
+ \\
\end{tabular} & $?$ & $?$ & $\odot$ & $?$ & 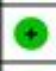 & 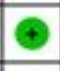 \\
\hline Monette J,Canada,2007 & + & $\odot$ & $\odot$ & O & $\odot$ & (†) & $?$ \\
\hline Llor C.Spain,2012 & O & $?$ & $?$ & $?$ & $\odot$ & + & $?$ \\
\hline Gjelstad S,Nonway,2013 & ๑) & $?$ & $?$ & $?$ & ๑) & $\odot$ & (†) \\
\hline Chen Y,China,2014 & + & $\odot$ & $\odot$ & $\odot$ & 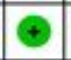 & $\odot$ & († \\
\hline Gulliford MC,England,2014 & () & $?$ & $?$ & $?$ & $\odot$ & † & ( \\
\hline Yang L,China,2014 & 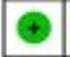 & (†) & $\odot$ & $\odot$ & ( & $\odot$ & - \\
\hline Hürlimann D,Switzerland,2015 & 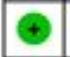 & $?$ & $\odot$ & $?$ & ๑ & $\odot$ & $?$ \\
\hline Ferrat E,France,2016 & (†) & $\oplus$ & $?$ & + & 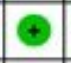 & + & (†) \\
\hline Qiu JG,China,2016 & \begin{tabular}{|l|} 
\\
\end{tabular} & $?$ & $?$ & $?$ & 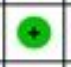 & + & $?$ \\
\hline Velden AW,Netherlands, 2016 & ๑) & $?$ & $?$ & $?$ & + & (†) & $?$ \\
\hline Vervioet M,Netherland,2016 & (†) & $?$ & () & $?$ & + & (†) & $?$ \\
\hline Lee MHM,Singapore,2017 & () & () & (†) & 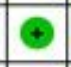 & $\odot$ & ๑ & $?$ \\
\hline Tang YQ,China,2017 & ๑) & $\odot$ & $?$ & $\odot$ & $\odot$ & $\odot$ & $?$ \\
\hline Wei XL,China,2017 & (†) & $\odot$ & $\odot$ & $\odot$ & $\odot$ & † & (†) \\
\hline Dekker ARJ,England,2018 & 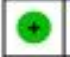 & $?$ & $?$ & $\odot$ & ( & $\odot$ & - \\
\hline Magin $P$, Australia,2018 & O & 0 & 0 & $?$ & - & + & $?$ \\
\hline Gulliford MC,England,2019 & - & 3 & $\odot$ & $\odot$ & (-) & $\odot$ & (-) \\
\hline
\end{tabular}

\section{Figure 2}

Risk of bias summary 


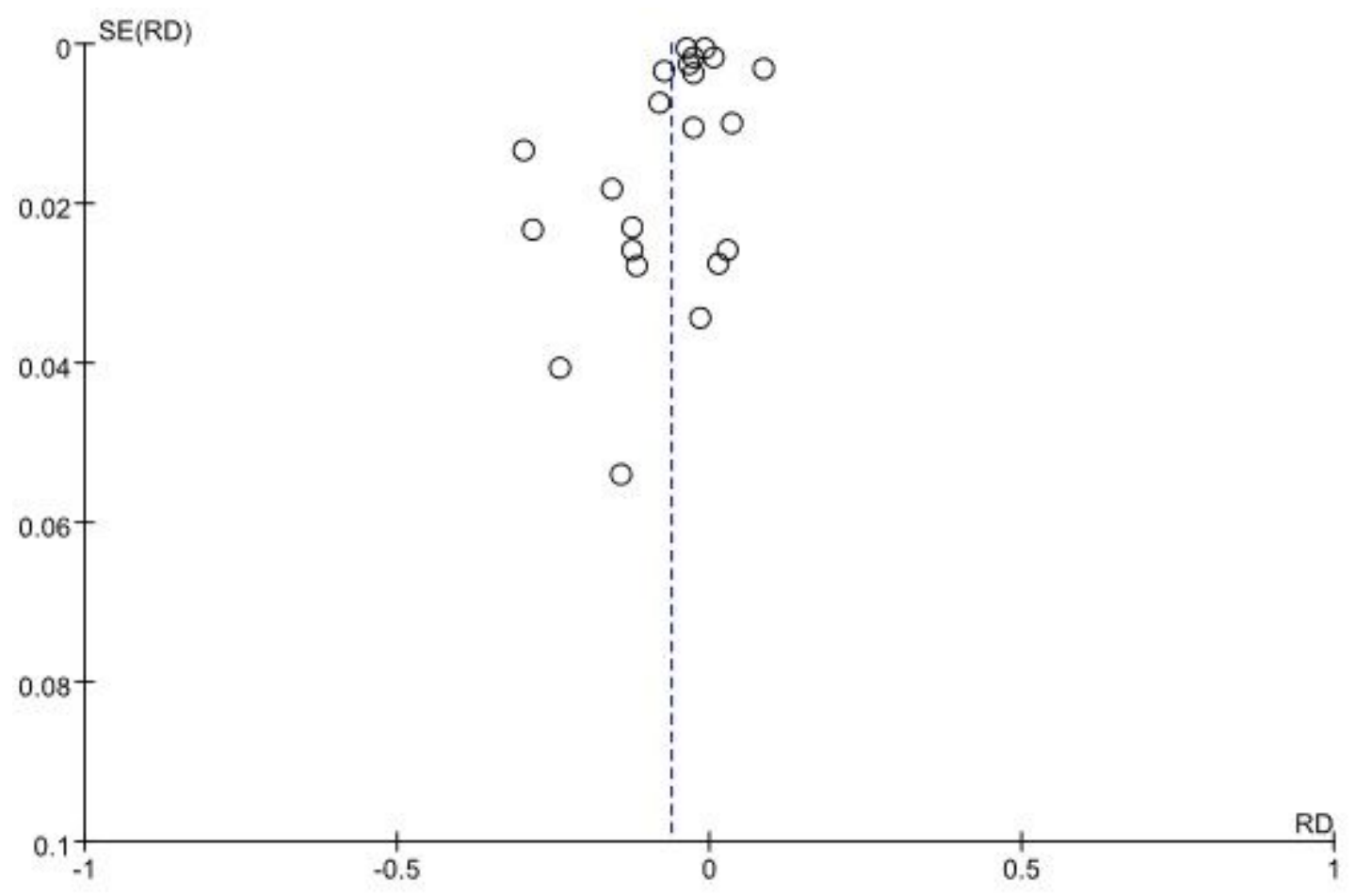

Figure 3

Inverted funnel plot of the effects of interventions on doctors' antibiotic prescription rates

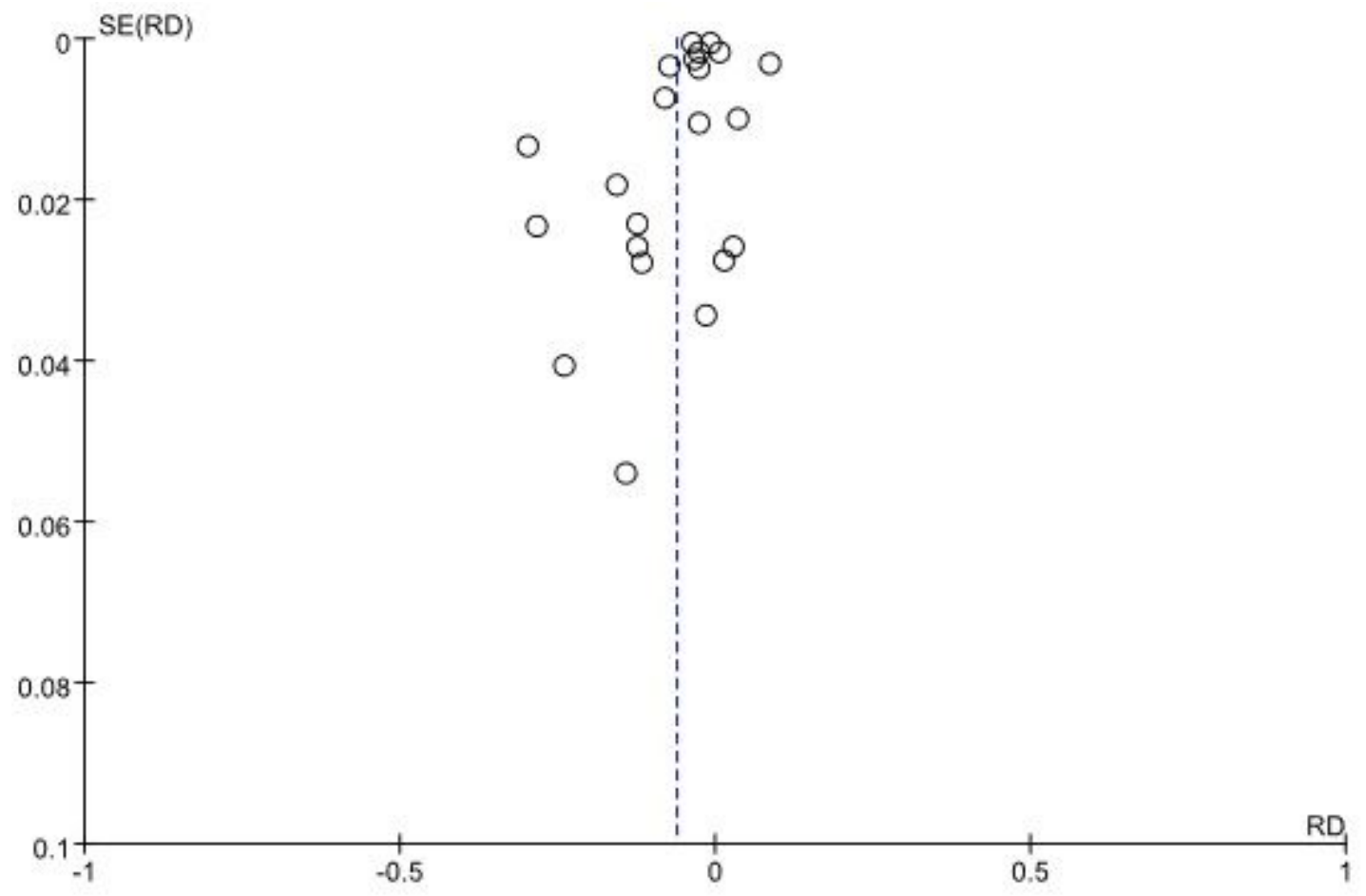

Figure 3

Inverted funnel plot of the effects of interventions on doctors' antibiotic prescription rates 


\section{Supplementary Files}

This is a list of supplementary files associated with this preprint. Click to download.

- PRISMAscreeningflowchart.pdf

- Pubmeddatabasesearchstrategy289.csv

- Table1.pdf

- Table2.pdf

- Table2.pdf

- Table3.pdf 